\title{
Standardization in maze procedure: a step towards a better future
}

\author{
Ovidio A. García-Villarreal \\ Department of Cardiac Surgery, Hospital Zambrano-Hellion, Monterrey, Mexico \\ Correspondence to: Dr. Ovidio A. García-Villarreal. Sierra Nayarita 143, Virginia Tafich, 66374, Santa Catarina, Nuevo León, Mexico. \\ Email: ovidiocardiotor@gmail.com. \\ Comment on: Musharbash FN, Schill MR, Sinn LA, et al. Performance of the Cox-maze IV procedure is associated with improved long-term survival \\ in patients with atrial fibrillation undergoing cardiac surgery. J Thorac Cardiovasc Surg 2018;155:159-70.
}

Submitted Aug 08, 2018. Accepted for publication Aug 22, 2018.

doi: $10.21037 /$ jtd.2018.08.131

View this article at: http://dx.doi.org/10.21037/jtd.2018.08.131

It is a well-known fact that patients with atrial fibrillation (AF) have an increased chance of stroke (1), heart failure (2) and death (3). Speaking about stroke rate, the sole presence of non-valvular AF increases this rate by 5 -fold, and when it is about valvular-AF, the stroke rate goes up by more than 17-fold (4). In addition, patients with preoperative AF undergoing cardiac surgery have a worse outcome and long survival rate $(5,6)$. Musharbash et al. (7) have demonstrated that by performing the maze procedure in a selected group of patients with preoperative $\mathrm{AF}$, survival rate is better when comparing with those having $\mathrm{AF}$ which was left untreated at the moment of concomitant cardiac surgery. In fact, this is the central core of the discussion in this paper.

Current guidelines for the surgical treatment of AF from the STS have improved the class of recommendation as well as the level of evidence for each of the surgical indications for $\mathrm{AF}(8)$. Most of them are now an indication Class I Level of Evidence A or B, or IIa B, depending on the specific situation surrounding a given case with AF. However, trends for surgical ablation for AF in 2014 do not go beyond $48.3 \%$ of patients having preoperative AF undergoing concomitant cardiac surgery in USA (9). Surprising as it may seem, this rate is clearly too low, and the question is what is going on, if we have the proper tools in our hands.

The maze procedure needs to be accurately performed in order to get the best results. Cox et al. (10) have described a success rate superior than $90 \%$ in recovering sinus rhythm. Schaff et al. (11), Schill et al. (12), Ad et al. (13), all of them have reported the same sinus rhythm conversion rate after maze higher than $85 \%$ at 1 year follow-up. Even though evidence is in favor of the maze procedure in eliminating
$\mathrm{AF}$, the weight of the evidence has been low or moderate to identify strong conclusions in terms of morbidity or mortality $(14,15)$. However, we must not fall into the error to lightly analyze these numbers. When all the tricks of the trade are not well-known, things can turn out wrong. And here is where the trouble begins. The first thing we should bear in mind is that the maze procedure must always be performed as a full bi-atrial lesion pattern, regardless the underlying pathology causing the AF. Dr. Cox et al. have described it in a flawless way (16). And this is my first criticism: judging from my experience, many surgeons just perform a "left-sided" maze, with no touching the right atrium. As a general rule, the lower the number of incisions or burn lines in the maze procedure, the lower the success after maze.

Another important issue is the way of anchoring the incisions or lines on the native mitral and tricuspid annuli as well as each one with the others. This is especially true when it is all about the mitral line over the mitral isthmus. The mitral isthmus region is a real challenge for the inexperienced surgeon. Using bipolar radiofrequency ablation or "cut-and-sew" plus cryolesion in this anatomic area is an absolute must. The innermost extreme of the mitral line over the mitral annulus is almost impossible to be exclusively performed by means of the bipolar radiofrequency clamp. This area is so thick that there is no guarantee that the bipolar clamp can deliver radiofrequency energy through the full thickness of tissue of more than $2 \mathrm{~cm}$ in depth. In addition to this, there are some striated muscle fibers crossing over the external surface of the coronary sinus which can conduct the electric impulse between both atria (17), which may give rise to 
postoperative peri-mitral flutter up to $15-20 \%$ of cases when cryoablation is not performing from outside the heart over the coronary sinus $(18,19)$. Alternatively, unipolar RF ablation can be applied on the mitral line from inside the heart. However, one cannot be sure about the transmurality nor the uniformity of the burn line (20).

Another alive issue is the way of performing the maze procedure. In respect thereof, we need to understand once and for all that there are only three possible ways to properly perform the maze procedure: (I) cut-and-sew plus cryoablation over critical areas (coronary sinus from outside the heart, and mitral and tricuspid annuli from inside the heart), (II) cryoablation alone all along the whole procedure, and (III) bipolar RF ablation plus cryoablation over critical areas. There is no other possible way to correctly perform the maze procedure (21). Incredible though it may seem, one can still find an enormous heterogeneity when comparing several studies about maze procedure. In other words, briefly speaking, there is a lack of standardization for the maze procedure. As a result, common findings in some meta-analyses or systematic reviews do not reflect what is really happening with these patients after maze procedure. Moreover, while close attention needs to be paid to long term survival after maze, a full and true standardization in surgical technique should be a priority.

On the other hand, another important worrying issue is the fact that most of the times the researchers working in a given group are not cardiac surgeons. As a consequence, there is not an adequate material selection in terms of appropriateness of the procedure due to the lack of surgical knowledge. For example, we cannot include a series in which unipolar RF ablation was used to do most of the burn lines into another one utilizing exclusively cryotherma or cut-and-sew. The same is applied to the type of lesion pattern used. Left-sided maze, partial maze, mini-maze, excluding/resecting or not the left atrial appendage should not be included in the same series containing true maze cases consistent in a full bi-atrial lesion pattern, with left atrial appendage removal made under the principles we stated out above. The bottom line of all this is a bias result. We need much more randomized control trials following a highly precise, very well-standardized surgical protocol (with no changes as far as possible) in order to get stronger conclusions. This is the only way to obtain enough material for true meta-analyses.

With this framework, we should recognize the capital importance of this article by Musharbash et al. (7). What is truly important here is the final outcome achieved by this group. This article has made very clear that long-term survival of patients having AF is much better when the maze procedure is performed. Kaplan-Meier analysis was in favor of the maze procedure group $(\mathrm{P}=0.004)$. Ten year survival was $62 \%$ vs. $42 \%(\mathrm{P}=0.014)$ for maze procedure vs. untreated AF, respectively. Another striking fact in this article was the comparison of patients (previously matched to those underwent maze procedure) between those with untreated $\mathrm{AF}$ and those without preoperative AF. Multivariate analysis using a Cox-proportional hazards model found out $\mathrm{AF}$ as a predictor of mortality with hazard ratio of 1.38 (95\% CI, 1.04-1.83, $\mathrm{P}=0.025$ ).

This article exemplifies the strength generated by following a very specific working line with no or minimum changes. Dr. Cox's pioneering works go all the way back to the end of $80 \mathrm{~s}$. Indeed, the main principles of the maze procedure have been preserved intact as since its inception and are still upheld at Barnes-Jewish Hospital, in St. Louis, Mo. Not surprisingly, the authors working under the direction of Dr. Damiano Jr. have found out excellent outcomes in this series (4).

\section{Acknowledgements}

None.

\section{Footnote}

Conflicts of Interest: The author has no conflicts of interest to declare.

\section{References}

1. Wolf PA, Abbott RD, Kannel WB. Atrial fibrillation as an independent risk factor for stroke: the Framingham Study. Stroke 1991;22:983-8.

2. Wang TJ, Larson MG, Levy D, et al. Temporal relations of atrial fibrillation and congestive heart failure and their joint influence on mortality: the Framingham Heart Study. Circulation 2003;107:2920-5.

3. Benjamin EJ, Wolf PA, D'Agostino RB, et al. Impact of atrial fibrillation on the risk of death: the Framingham Heart Study. Circulation 1998;98:946-52.

4. Wolf PA, Dawber TR, Thomas HE Jr, et al. Epidemiologic assessment of chronic atrial fibrillation and risk of stroke: the Framingham study. Neurology 1978;28:973-7.

5. Ngaage DL, Schaff HV, Mullany CJ, et al. Does preoperative atrial fibrillation influence early and late 
outcomes of coronary artery bypass grafting? J Thorac Cardiovasc Surg 2007;133:182-9.

6. Wang B, Xu ZY, Han L, et al. Impact of preoperative atrial fibrillation on martality and cardiovascular outcomes of mechanical mitral valve replacement for rheumatic mitral valve disease. Eur J Cardiothorac Surg 2013;43:513-9.

7. Musharbash FN, Schill MR, Sinn LA, et al. Performance of the Cox-maze IV procedure is associated with improved long-term survival in patients with atrial fibrillation undergoing cardiac surgery. J Thorac Cardiovasc Surg 2018;155:159-70.

8. Badhwar V, Rankin JS, Damiano RJ Jr, et al. The Society of Thoracic Surgeons 2017 Clinical Practice Guidelines for the Surgical Treatment of Atrial Fibrillation. Ann Thorac Surg 2017;103:329-41.

9. Badhwar V, Rankin JS, Ad N, et al. Surgical Ablation of Atrial Fibrillation in the United States: Trends and Propensity Matched Outcomes. Ann Thorac Surg 2017;104:493-500.

10. Cox JL, Ad N, Palazzo T, Fitzpatrick S, et al. The MazeIII procedure combined with valve surgery. Semin Thorac Cardiovasc Surg 2000;12:53-5.

11. Schaff HV, Dearani JA, Daly RC, et al. Cox-maze procedure for atrial fibrillation: Mayo Clinic experience. Semin Thorac Cardiovasc Surg 2000;12:30-7.

12. Schill MR, Musharbash FN, Hansalia V, et al. Late results of the Cox-maze IV procedure in patients undergoing coronary artery bypass grafting. J Thorac Cardiovasc Surg 2017;153:1087-94.

13. Ad N, Henry L, Hunt S, et al. Results of the Cox-Maze III/IV procedure in patients over 75 years old who present for cardiac surgery with a history of atrial fibrillation. J Cardiovasc Surg (Torino) 2013;54:281-8.

14. Reston JT, Shuhaiber JH. Meta-analysis of clinical outcomes of maze-related surgical procedures for medically refractory atrial fibrillation. Eur J Cardiothorac Surg 2005;28:724-30.

15. Huffman MD, Karmali KN, Berendsen MA, et al. Concomitant atrial fibrillation surgery for people undergoing cardiac surgery. Cochrane Database Syst Rev 2016;(8):CD011814.

16. Cox JL, Jaquiss RD, Schuessler RB, et al. Modification of the maze procedure for atrial flutter and atrial fibrillation II. Surgical technique of the maze III procedure. J Thorac Cardiovasc Surg 1995;110:485-95.

17. Chauvin M, Shah DC, Haïsaguerre M, et al. The anatomic basis of connections between the coronary sinus musculature and the left atrium in humans. Circulation 2000;101:647-52.

18. Cox JL. A brief overview of surgery for atrial fibrillation. Ann Cardiothorac Surg 2014;3:80-8.

19. Cox JL, Ad N. The importance of cryoablation of the coronary sinus during the Maze procedure. Semin Thorac Cardiovasc Surg 2000;12:20-4.

20. Ad N, Damiano RJ Jr, Badhwar V, et al. Expert consensus guidelines: examining surgical ablation for atrial fibrillation. J Thorac Cardiovasc Surg 2017;153:1330-54.

21. Ad N, Holmes SD, Rongione AJ, et al. Does surgical ablaiton energy source affect long-term success of the concomitant Cox-maze procedure? Ann Thorac Surg 2017;104:29-35.
Cite this article as: García-Villarreal OA. Standardization in maze procedure: a step towards a better future. J Thorac Dis 2018;10(Suppl 33):S3887-S3889. doi: 10.21037/jtd.2018.08.131 